\title{
INTEGRATED STUDY OF THE BEATA VERGINE ASSUNTA DOME WITH STRUCTURE FROM MOTION AND DIAGNOSTIC APPROACHES
}

\author{
S.M. Grillo ${ }^{1}$, E. Pilia ${ }^{2}$, G. Vacca ${ }^{2 *}$ \\ ${ }^{1}$ DSCG Dept. of Chemical and Geological Science, University of Cagliari, Italy - grillo@unica.it \\ ${ }^{2}$ DICAAR, Dept. of Civil-Environmental Engineering and Architecture, Cagliari, Italy - (epilia, vaccag)@unica.it
}

Commission VI, WG VI/4

KEY WORDS: Cultural Heritage, SfM, photogrammetry, minero-petrographic analysis; open source

\begin{abstract}
:
Between 1839 and 1849, the architect Gaetano Cima built a very interesting neoclassical church with a central plan, covered by a dome about 20 meters in diameter in Guasila (in the province of Cagliari, Italy). Already during the construction, Cima highlighted a series of problems related to the quality of the materials used, the technical skills of the builders, and the cost-cutting measures taken during construction, which proved to be the cause of the deterioration that characterised the life of the building and the numerous restorations works that have occurred over time. Faced with this situation, the Municipality of Guasila has commissioned a group of researchers from the DICAAR (Department of Civil, Environmental and Architectural Engineering) of the University of Cagliari to carry out a multidisciplinary study aimed at defining in a complete and exhaustive way the state of conservation of the church. Overall, this study concerned historical-critical analysis, geometric-architectural survey, structural survey and analysis, analysis of materials and the study of foundations involving architectural historians, geomatics, structuralists, petrographers and geophysicists. In detail, this paper presents the integrated results obtained from archival research on the restoration works, the close range photogrammetric (CRP) and minero-petrographic surveys performed for implementing the knowledge of the painted dome of this basilic, characterised by several static problems since its construction. The support of the three fields of research has allowed not only to define an in-depth level of information concerning the origins of the issues in terms of geometries, materials and building techniques for the design of future interventions of conservation of the structures, but also to define potentialities and accuracy of this interoperable approach in the study of other similar case studies.
\end{abstract}

\section{INTRODUCTION}

The whole architectural heritage constituted by historical monumental buildings such as churches and residential palaces represent a collective memory of the past, identity symbols for the society and attractions for tourists. Therefore, the knowledge and protection of this patrimony from phenomena of obsolescence or ruination takes undoubtedly importance, especially in Italy where this inheritance is huge especially through the old town centres. For that reason, in the last few years, local governments led their interest to the integrated study of measuring and monitoring methods which, quickly and low cost, allow to define accurately the origins of the decay (Giannattasio et al., 2013). The most frequent protocol of monitoring and control can be classified as follows: assessment of the deformation and damage caused by natural calamities (e.g. earthquakes), or malicious (e.g. fires); assessment of the surface decay caused by weather conditions; evaluation of the present precarious structural of structures with respect to its initial project; verification of the result carries out by craftmanship. The main goal, thus, is to identify techniques and tools that allow accurate and reliable knowledge of structures in terms of geometry, forms, materials and techniques easy to carry out and not too expensive (Battini et al., 2017; Vacca et al., 2016).

Starting from a detailed archival investigation, survey and detailed geometrical restitutions, the study has been supported by the detailed minero-petrographic study of materials or understanding their quality and state of conservation. In detail, the archive analysis is conducted consulting the archive of the
Superintendence of Architecture, Landscape, Historical, Artistic and Ethno-anthropological Heritage of the Provinces of Cagliari and Oristano (document and photographic archives); the geometric survey in TLS and CRP surveys have been performed and processed with open source software using the "Structure from Motion" approach: VisualSfM, developed by Chanchang $\mathrm{Wu}$ in collaboration with the University of Washington and Google, and Regard 3D. Photogrammetric surveys have also been processed with the Photoscan commercial software by Agisoft. Finally, all the material and diagnostic analyses have been carried out in the, LabMAST - Mediterranean Laboratory for Historical materials and architectures.

The presented protocol has been experimented on the basilic of the Beata Vergine Assunta in Guasila (Sardinia) and in particular on its dome, chosen for its relevant historical and aesthetical values as well as for the complex issues concerning the state of conservation of its structures and painted surfaces that need to be soon restored.

\section{THE BASILIC OF THE BEATA VERGINE ASSUNTA}

\subsection{History construction}

The Basilic, designed in 1839 by one of the most important architects in the ninetieth Sardinia context, Gaetano Cima, and officially open to the cult in the 1852 , was built in partial overlapping on an older ruined Baroque church demolished for its state of obsolescence (Virdis et al., 2003). From its former structures, today we can see only the bell tower, close to the main rounded body of the monument added later (figure 1). It is

\footnotetext{
* Corresponding author
} 
a 'temple' with a central plan, considered as first example of neoclassic architecture on the local panorama of religious architectures. The church is preceded by a pronao constituted by six Doric columns and two lateral pillars, that support a triangular tympanum with the inscription of the monument to the Vergine Assunta. The central body, wide 28 metres of diameter, is covered by an ample dome with a lantern based on four massive pillars each of which is placed side by side by two elegant Doric columns opening to six lateral chapels. The building site, opened in 1842, saw a series of difficulties related to the scarce ability of the craftsmanship and the contractor Mr. Crobu; it was involved in several problematic events as well as errors of construction for the structures and the decorative apparatus. Therefore, it does not surprise that, during the 166 years of life, the church has been object of numerous interventions both of restauration and consolidation. The first alarm concerning static issues and cracks appeared very soon in 1897, when the Superintendent Vivanet, asked to the Prefecture to examine a project by the engineering Loni, recommending the use of the cement, instead of the ordinary mortar, for profiling the lesions of the dome. This can be considered only the beginning of a controversial series of interventions, especially related to the dome and the vaults of this basilic.

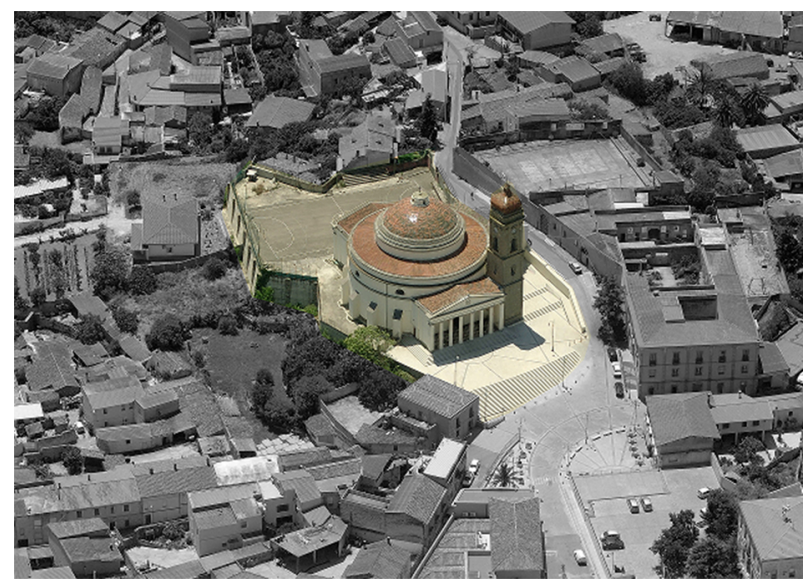

Figure 1. Aerial view of the Basilic (Pilia E.).

\subsection{The dome}

An element of significant value is the dome of this basilic, clearly inspired by the Pantheon in Roma, in this period example of innovation and classicism for all the religious architecture in Europe. The hemispheric structure, based on a tambour, is wide 16 metres and it is closed by a lantern replaced probably in $30 \mathrm{~s}$ during restoration works. As it has been confirmed by the thermographic analysis, the structure is built in two different materials: local sandstone for one third of the hemisphere and the rest in bricks according to the coeval building techniques. Internally, the dome is completely painted with 24 sectors constituted by geometric and floral elements designed by the same architect plainly influenced by the neoclassic style in terms of details and colours. Unfortunately, as already said, the poor ability of the builders and their scarce skills on similar structures drove towards several static problems, increased by the low quality of building materials. In 1978, the high level of rain infiltrations caused the detachment of around the $15 \%$ of the total surface of painted plasters $(400$ $\mathrm{mq}$ ), whereas the rest was characterised by several cracks. For that reason, a specific restoration work, financed by the Superintendence, was realised

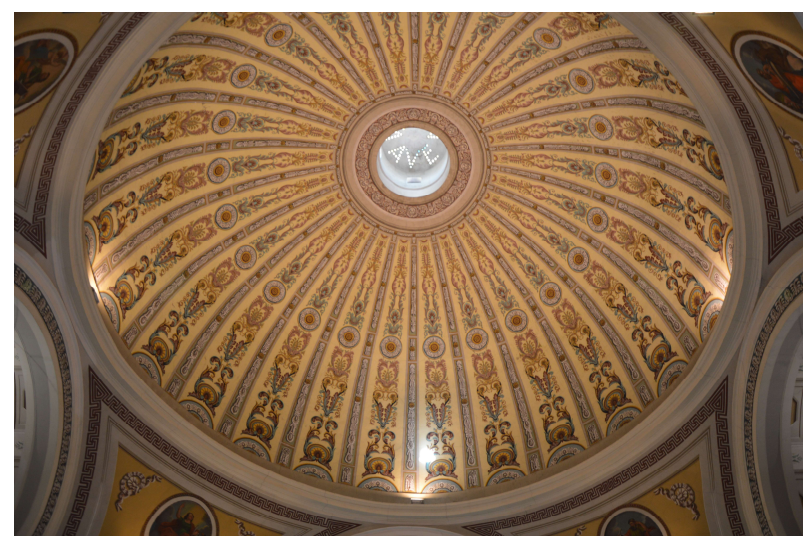

Figure 2. The internal view of the dome (Pilia E.).

repainting all the internal dome but leaving unsolved the real issues of its ongoing decay.

\subsection{The restoration works}

During all the twentieth century, the church has been object of several continuously restoration works without solving the real causes of its decay that year by year presented the same problems on the structures. The issues related the monument were mainly two: the diffused cracks on the masonry structures and the infiltrations of rainy water from the roofs. As concern the first ones, these were and are still located on the bearing walls, arches, vaults and on the dome where infiltrations are also causing the detachment of plasters on its decorative cornice.

From the 1948, a series of consolidation works have been carried out with the addition of iron bars and use of concrete mortars, completely incompatible with the structures. Then, in $90 \mathrm{~s}$, the construction of a new retained tried to support the static pressure of the structure for solving the static issues of the structures but unsuccessfully. As concerns the further problems of rainy waters, these started during the construction site as reported on the letters of the priest in 1949 and they continued throughout all the century later (Virdis et al., 2003).

In 70 s a sudden worsening required an intervention on the dome, in these years seriously in danger for the high load of the waters and the consequent detachment of the painted plasters (figure 2). After the closing of the church, in 1978 the ing. Rollo proposed a series of intervention for the waterproofing of the roofs and the conservative restoration of the paintings. These interventions can be considered the most important for understanding the current configuration of the dome, widely consolidated and re-plastered with concrete mortars and repainted in acrylic temper. In the same years the roofs were completed demolished, refurbished with integration of bricks and concrete mortars, metallic grids and a new system of drainpipe for guarantee the efficiency of water disposal.

Then, in $80 \mathrm{~s}$ and $90 \mathrm{~s}$, other interventions of consolidation, concerning the roofs have been conducted without success (Sanjust et al., 2018) and despite the long series of interventions we still see the dome with the same decay problems: presence of humidity, infiltrations of water, diffused lesions.

For that reasons, precisely for this structural element, the archival research has been supported by the diagnostic study of characterisation of materials (natural and artificial), considering the original ones and those linked to the later restoration additions and by the geometric study of forms and anomalies with the support of Structure From Motion tools and open source programmes. 


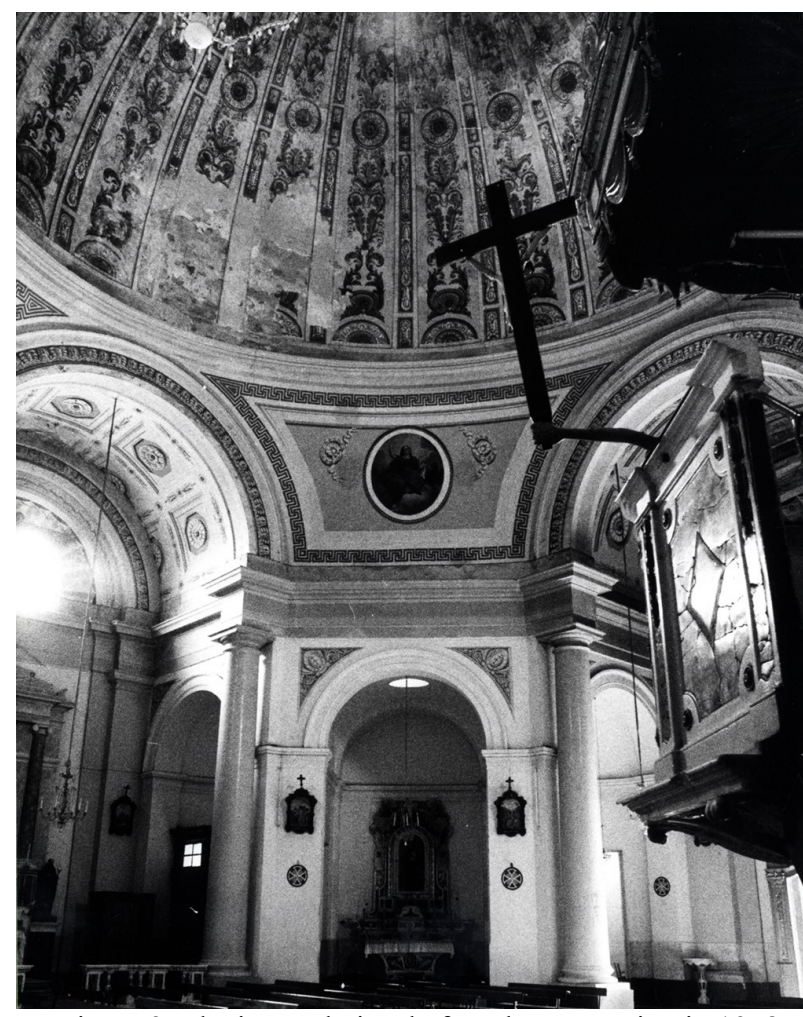

Figure 3. The internal view before the restoration in 1978 (Superintendence of BAPSAE - Provinces of Cagliari and Oristano).

\subsection{Building materials}

The Sanctuary is placed site in the historical core of Guasila, sheet 548 Senorbì of the ISPRA Geologic map of Italy (scale 1:50.000) inherent to centre-southern Sardinia. This is a landscape characterized by a flat and hilly morphology called Trexenta, where Miocene and quaternary rocks appear mainly on the surface (Funedda et to the., 10). As it can be deduced by the geologic paper, the territory in which Guasila is placed, comes from the Miocene sedimentary complex described as RML: Silto- marl, alternated with levels of sandstones with strong volcanic. On the East of the village, instead, it can be found also a deposit of the Holocene. Overall, from the macroscopic analysis of the monument, it is clear that all the structures have been realized in local sandstones (figure 4), probably outcropped by neighbouring historical quarries close to the villages of Nuraminis-Samatzai and Pimentel. The sands instead, came from the site of de "Is Concas" in the same village of Guasila, nowadays closed.

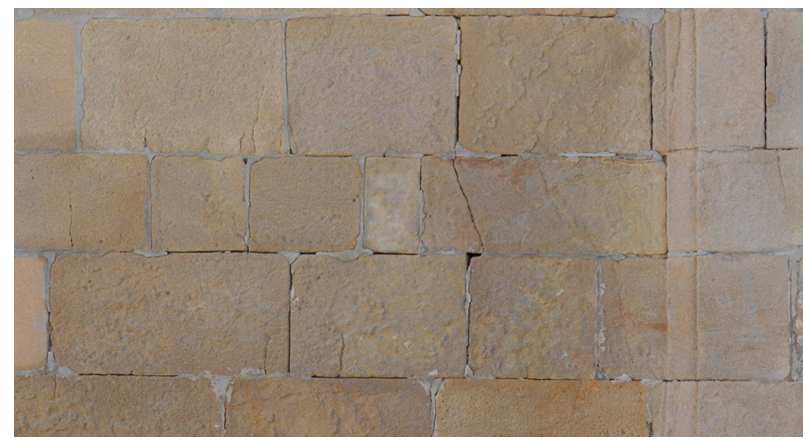

Figure 4. Sandstone masonry of the tower bell, built with the same local material (Pilia E.)

\section{MATERIAL AND GEOMETRIC SURVEYS ON THE DOME}

\subsection{Minero-petrographic analysis}

The phase of material analysis has consisted in the systematic study of the natural and artificial stones, considering both those used in the building site and those used during the restoration works, allowing the identification of the materials, hypothesising their origin and the sites of extraction as well as the different typologies of weathering and decay.

Concerning the minero-petrographic nature of the materials, this has been carried out by means of the characterization of mortars and plasters considering composition, form, dimensions, granulometry of the aggregate, the typology of binder and the state of conservation. In detail, a reasoned sampling has been performed, with scalpel according with her "UNI NORMAL EN 16085:2012 Conservation of Cultural property - Methodology for sampling from materials of cultural property - General rulesICS: [97.195]." The number of samples, enough to represent the different present typologies, is the result of a preliminary investigation conducted on all the structures with the support of a crane used also for the endoscopic investigations.

Furthermore, the material investigation has been conducted in order to understand the stratigraphy of the dome surface. Specifically, significant samples (figure 5) were analysed according to the following protocol: selection of the reasoned sample; their study by means of transmitted and reflected light microscopy; study of the aggregate and of the binder separately by means of x-ray diffractometer. All these surveys have been carried out in the laboratories DICAAR and LabMAST Mediterranean Laboratory for Historical materials and architectures. with optical microscope in transmitted light Zeiss Atioplan and diffractometer Rigaku Ultima IV, in parallel optic, radiation $\mathrm{CuK} \alpha$ a $30 \mathrm{~mA}$; pattern $5^{\circ}-65^{\circ}$.

From the macroscopic analysis of the material samples results clear that all the bearing structures have been realized in local sandstone as also confirmed by the indications furnished by the geotechnical surveys. As concerns the plasters (figure 3) instead, it can be confirmed the presence of three layers, with high probability linked to the restoration works. While C_02 is clearly a concrete mortar from the $80 \mathrm{~s}$ intervention of replastering and repainting with a thin layer of acrylic temper, the sample C_04 shows the same concrete layer and further historical lime mortar that shows a thinner aggregate and a lower aggregate/binder relationship. Finally, C_05 has the same composition of the deeper layer of C_ 04 so, it could be part of original lime mortars designed by the ${ }^{-}$ima.

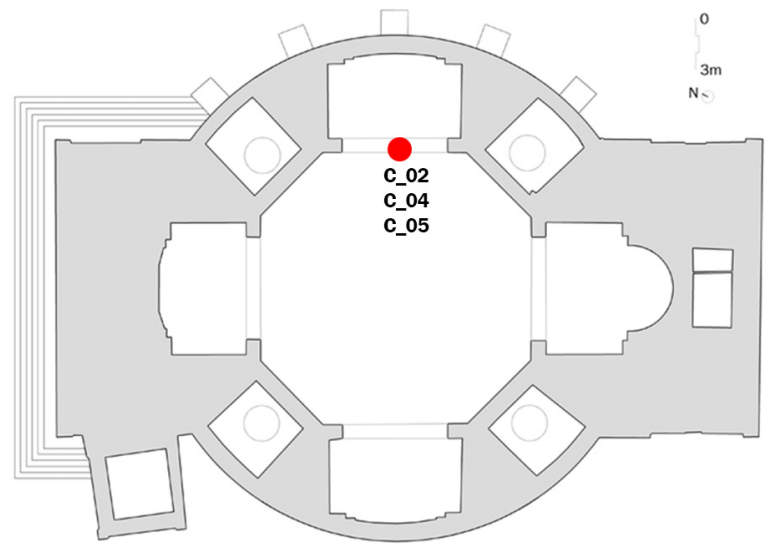

Figure 5. Map of the samples (Pilia E.) 

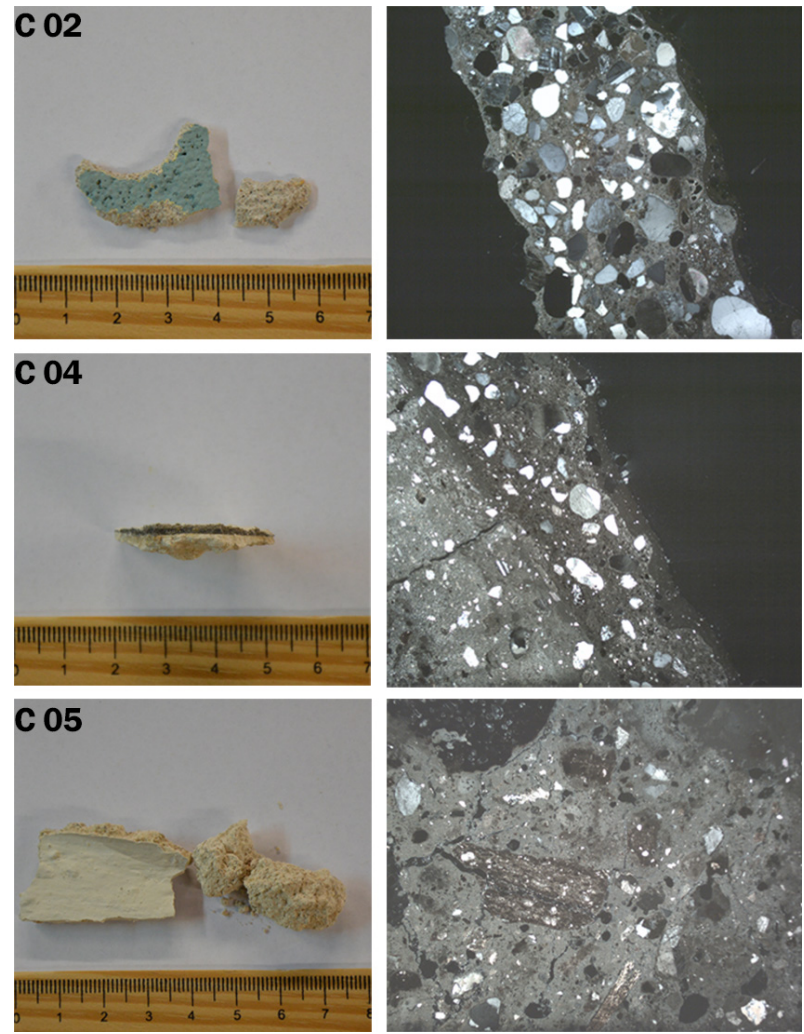

Figure 6. Minero-petrographic analysis. From the left: macro photo; thin sections under the optical microscope in

Transmitted Light (Laboratory analysis: Grillo S.M., LabMaST. Graphic elab: Pilia E.).

\subsection{Geomatic survey}

As concerned the geometric survey of the dome, it has been carried out with a Terrestrial Laser Scanner technique (TLS) and a Close-Range Photogrammetry (CRP) by means of a Structure from Motion approach (SfM). The aim was to verify the coherence of the Basilic with the original configurations and possible static issue, the presence of important architectural element, materials and anomalies as well as the level of accuracy possible reachable with the low cost photogrammetry system.

In particular, in low-cost Close Range Photogrammetric (CRP) system the images were processed with open source software using the "Structure from Motion" approach: VisualSfM, developed by Chanchang $\mathrm{Wu}$ in collaboration with the University of Washington and Google, and Regard 3D. Photogrammetric surveys have also been processed with the Photoscan commercial software by Agisoft.

The low-cost Close Range Photogrammetric (CRP) system included two non-professional digital camera. First camera is a Canon Powershot S110 with a 1/1.17' sensor and a $12 . \mathrm{m}$ Megapixel resolution; zoom 5x: 5.2 (G) -26.0 (T) $\mathrm{mm}$ (equivalenti to $35 \mathrm{~mm}$ : $24(\mathrm{G})-120(\mathrm{~T}) \mathrm{mm}$ on a $24 \mathrm{~mm}$ film); the output data formats are Exif 2.3 (JPEG) and RAW (CR2 Canon original). The second digital camera is a Canon EOS M3 with a sensor CMOS $22.3 \times 14.9 \mathrm{~mm}$ and a 24.2 Megapixel resolution; objective EF-S $18-55 \mathrm{~mm}$; the output data formats are Exif 2.3 (JPEG) and RAW (CR2 Canon original).

With the PowerShot S110 camera the dome was surveyed from the ground (distance from the camera position to the dome between 14 and $24 \mathrm{~m}$ ), while the photogrammetric survey with the EOS M3 was performed using a mobile platform, with distances between the camera position and the dome varying between 3 and $8 \mathrm{~m}$.

The dome was also surveyed with the Faro Focus 3D TLS. Only one scan was carried out, from ground level, at a resolution setting of $1 / 4$ with $3 x$ quality, corresponding to a resolution of 7 $\mathrm{mm} / 10 \mathrm{~m}$. The validation was done using the Cloud Compare open source software.

The OS software used are instead VisualSfM and Regard3D. Furthermore, it has been used Photoscan - Agisoft, the commercial software widely used and tested.

The SfM is a low-cost photogrammetric method for highresolution topographic reconstructions. The SfM operates under the same basic tenets of the stereoscopic photogrammetry, namely that the 3D structure can be resolved from a series of overlapping images. However, they fundamentally differ because in SfM, the geometry of the scene, camera positions, and orientation is solved automatically without points known. The points are solved simultaneously using a highly redundant, iterative bundle adjustment procedure, based on a database of features automatically extracted from a set of multiple images with a high degree of overlap. The approach is most suited to sets of images with a high degree of overlap that capture the full three-dimensional structure of the scene viewed from a wide array of positions, or as the name suggests, images derived from a moving sensor (Szeliski, 2010; Westoby et al., 2012; Vacca et al., 2017).

In table 1 it can be seen the characteristics of the evaluated software tools.

\begin{tabular}{|c|c|c|c|}
\hline & VisualSfM & Regard3D & Photoscan \\
\hline $\begin{array}{l}\text { Dense } \\
\text { Matching }\end{array}$ & PMVS/CMVS & openMVS & integrated \\
\hline License & Freeware & $\begin{array}{l}\text { MIT } \\
\text { License }\end{array}$ & Proprietary \\
\hline $\begin{array}{l}\text { Camera } \\
\text { Model } \\
\text { parameters } \\
\text { (in } \\
\text { addition to } \\
\text { fx, fy, cx, } \\
\text { cy) }\end{array}$ & $\begin{array}{l}\text { k1 (one set of } \\
\text { parameters for } \\
\text { each image) }\end{array}$ & $\begin{array}{l}\text { various } \\
\text { models; } \\
\text { k1 }\end{array}$ & $\begin{array}{l}\mathrm{k} 1, \mathrm{k} 2, \mathrm{k} 3, \\
\mathrm{p} 1, \mathrm{p} 2 \\
\text { one model } \\
\text { for all } \\
\text { images }\end{array}$ \\
\hline $\begin{array}{l}\text { Interface } \\
\text { (GUI or } \\
\text { CLI) }\end{array}$ & GUI + CLI & GUI & GUI+CLI \\
\hline $\begin{array}{l}\text { Feature } \\
\text { Detector }\end{array}$ & SIFT & AKAZE & Proprietary \\
\hline $\begin{array}{l}\text { Geo- } \\
\text { referencing }\end{array}$ & $\begin{array}{l}\text { With external } \\
\text { tool after dense } \\
\text { matching }\end{array}$ & $\begin{array}{l}\text { With } \\
\text { external tool } \\
\text { after dense } \\
\text { matching }\end{array}$ & $\begin{array}{l}\text { During } \\
\text { bundle } \\
\text { adjustment }\end{array}$ \\
\hline $\begin{array}{l}\text { Hardware } \\
\text { specialties }\end{array}$ & $\begin{array}{l}\text { Video card } \\
\text { required }\end{array}$ & & \\
\hline
\end{tabular}

Table 1: Characteristics of the evaluated software tools.

The images were taken by an elevated platform used also for conducting other diagnostic investigations at the base of the dome. 97 photos have been acquired by the EOS M3, with the Powershot 101 and processed with different software on an HP Z420 workstation with 64 GB RAM, Intel Xeon E5-16200 3.60 $\mathrm{GHz}$ CPU, and NVIDIA Quadro K2000 video card. 
The image processing workflow follows the standard steps of SfM softwares with the solution of the Bundle Adjustment on sparse point cloud, external orientation of the block and generation of the dense point cloud. Instead, with the Photoscan software, all the images have been elaborated in UltraHigh, allowing the possibility to use dense point clouds with a high number of points but with long times of elaboration as well as with a Medium modality, saving time during the elaboration but with a lower number of points in the cloud. On table 2 it is reported a comparison between all the data acquired from the different surveys CRP and the elaboration conducted with different cameras and software.

\begin{tabular}{|c|c|c|c|c|}
\hline & images & parameter & n. points & Time \\
\hline $\begin{array}{c}\text { Photoscan/ } \\
\text { EOSM3 }\end{array}$ & 97 & UltraHigh & 114.453 .295 & 5 days \\
\hline $\begin{array}{c}\text { Photoscan/ } \\
\text { Powershot }\end{array}$ & 101 & UltraHigh & 27.091 .438 & $16 \mathrm{~h}$ \\
\hline $\begin{array}{c}\text { Photoscan/ } \\
\text { EOSM3 }\end{array}$ & 97 & Medium & 8.401 .015 & $6 \mathrm{~h}$ \\
\hline $\begin{array}{c}\text { Photoscan/ } \\
\text { Powershot }\end{array}$ & 101 & Medium & 1.712 .470 & $2 \mathrm{~h}$ \\
\hline VSFM/PS & 101 & & 696.736 & $2 \mathrm{~h}$ \\
\hline $\begin{array}{c}\text { Regard } \\
\text { 3D/PS }\end{array}$ & 101 & & 701.259 & $4 \mathrm{~h}$ \\
\hline
\end{tabular}

Table 2: Surveys data.

All the surveys CRP were georeferenced using $10 \mathrm{GCP}$ and the rms for all the surveys have been around $3-4 \mathrm{~cm}$. The figures 7 , 8 e 9 show the point clouds with VisualSfM, Regard 3D e Photoscan (Powershot UltraHigh) softwares.

Finally, the TLS survey has been carried out with the Faro Focus 3D. Only one scan was carried out, from ground level, at a resolution setting of $1 / 4$ with $3 x$ quality, corresponding to a resolution of $7 \mathrm{~mm} / 10 \mathrm{~m}$. In this way a point cloud with 9.309.845 points was obtained.

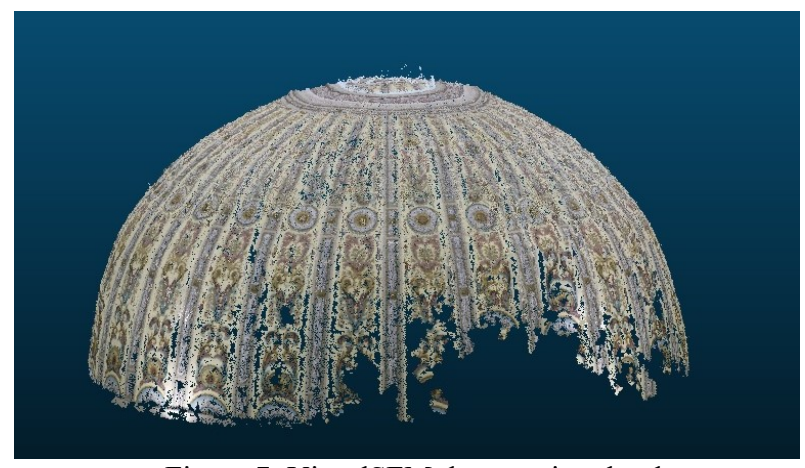

Figure 7: VisualSFM dense point cloud.

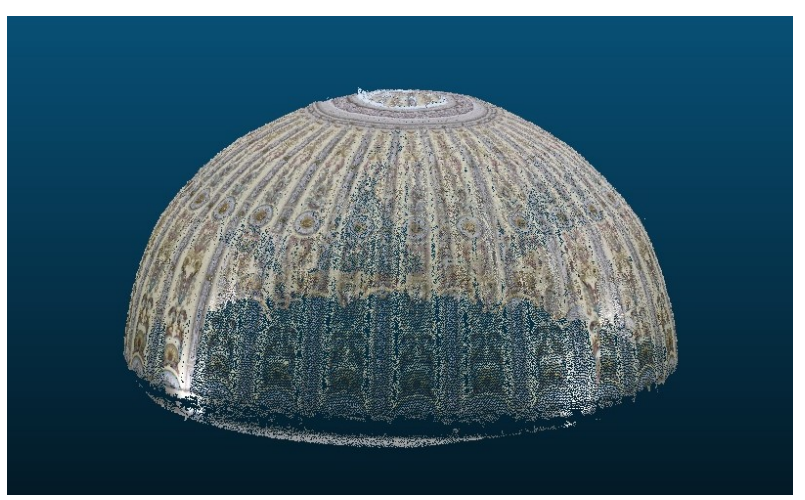

Figure 8: Regard 3D dense point cloud.

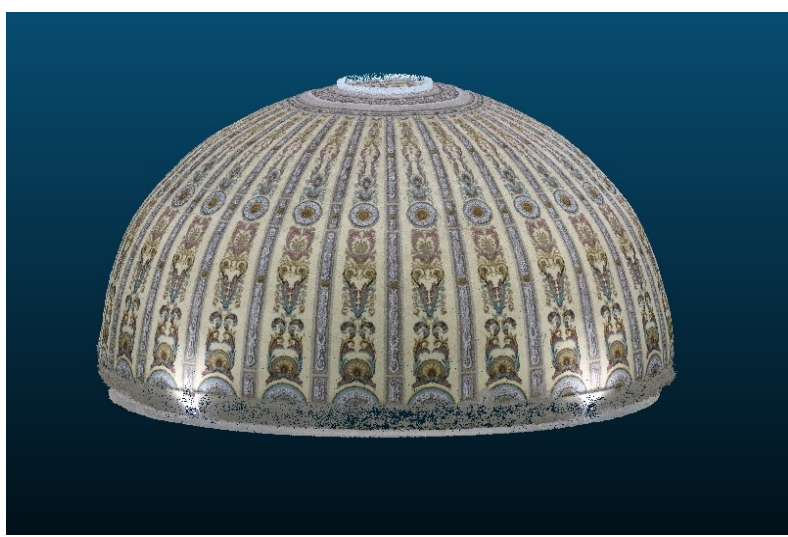

Figure 9: Photoscan dense point cloud.

\section{RESULTS}

The CRP dense point clouds have been compared with point cloud from the TLS survey. This comparison was done both comparing the measurements of distances taken on the point clouds obtained from different CRP surveys and different software and TLS surveys, and comparing the point clouds themselves using the CloudCompare software (Open Source Software). Specifically, this analysis was done by calculating the minimal distance between every point of the models using the nearest neighbour algorithm. Furthermore, the software allows the calculation of statistical values, such as the minimal distance, maximal distance, average distance, and standard deviation.

Tables 3 and 4 report the results of the comparisons between the point clouds obtained with TLS and the point clouds from Photoscan processed with UltraHigh and Medium parameters. Table 5 instead, reports the results of the comparisons between the point clouds obtained with TLS and the point clouds from VisualSfM and Regard 3D.

\begin{tabular}{|c|c|c|}
\hline Camera/Mode & EOS3/UltraHigh & Powershot/UltraHigh \\
\hline Min $(\mathrm{m})$ & 0 & 0 \\
\hline Max $(\mathrm{m})$ & 0.718 & 0.681 \\
\hline Mean $(\mathrm{m})$ & 0.032 & 0.035 \\
\hline Dev. Stand (m) & 0.066 & 0.065 \\
\hline
\end{tabular}

Table 3: Statistical values of the comparisons between the TLS data and the point clouds Ultrahigh.

\begin{tabular}{|c|c|c|}
\hline Camera/Mode & EOS3/Medium & Powershot/Medium \\
\hline Min $(\mathrm{m})$ & 0 & 0 \\
\hline Max $(\mathrm{m})$ & 0.665 & 0.526 \\
\hline Mean $(\mathrm{m})$ & 0.012 & 0.013 \\
\hline Dev. Stand $(\mathrm{m})$ & 0.065 & 0.053 \\
\hline
\end{tabular}

Table 4: Statistical values of the comparisons between the TLS data and the point clouds Medium.

\begin{tabular}{|c|c|c|}
\hline Camera/Mode & VSFM/Powershot & $\begin{array}{c}\text { Regard } \\
\text { 3D/Powershot }\end{array}$ \\
\hline Min (m) & 0 & 0 \\
\hline Max (m) & 1.064 & 0.688 \\
\hline Mean (m) & 0.015 & 0.007 \\
\hline Dev. Stand (m) & 0.044 & 0.035 \\
\hline
\end{tabular}

Table 5: Statistical values of the comparisons between the TLS data and the VisualSfM and Regard 3D point clouds 

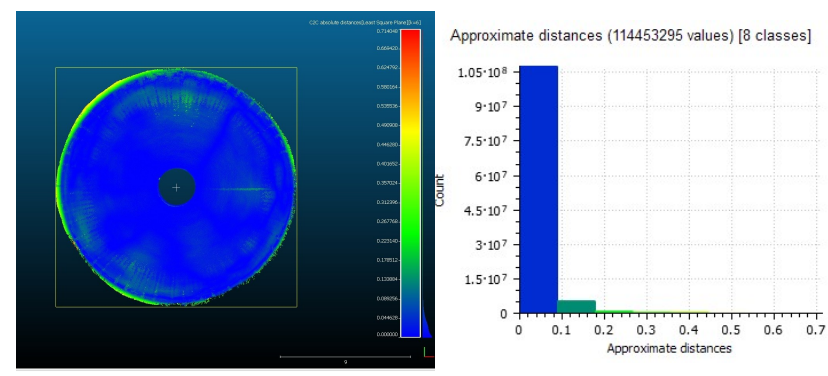

Figure 8: Discrepancy (m) map and histogram between the TLS point cloud and EOS3 - UltraHigh processing.
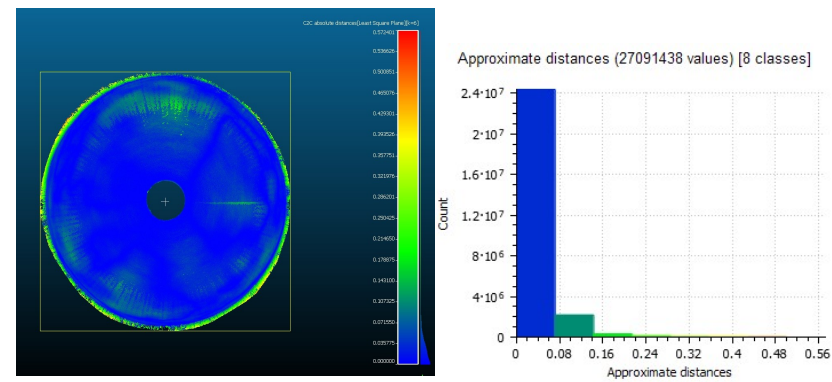

Figure 10: Discrepancy (m) map and histogram between the TLS point cloud and Powershot - UltraHigh processing.
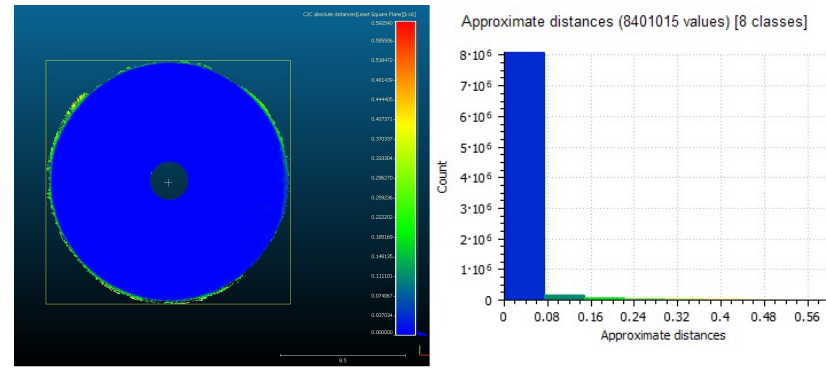

Figure 11: Discrepancy (m) map and histogram between the TLS point cloud and EOS3 - Medium processing.
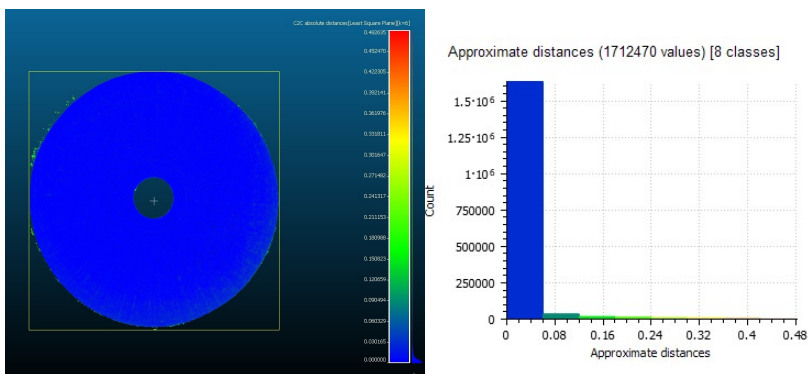

Figure 12: Discrepancy (m) map and histogram between the TLS point cloud and Powershot - Medium processing.
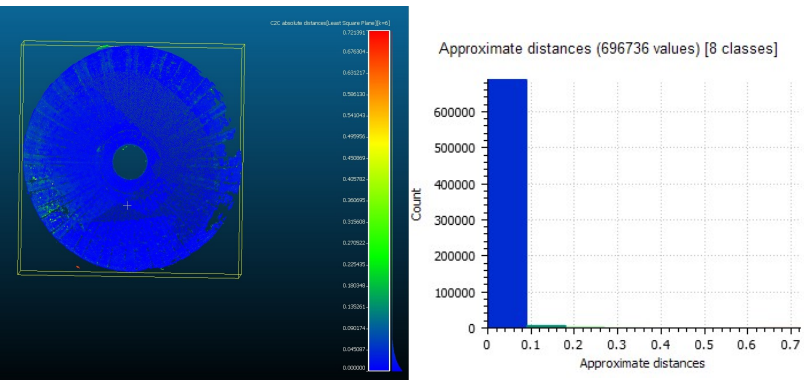

Figure 12: Discrepancy (m) map and histogram between the TLS point cloud and VisualSfM processing.
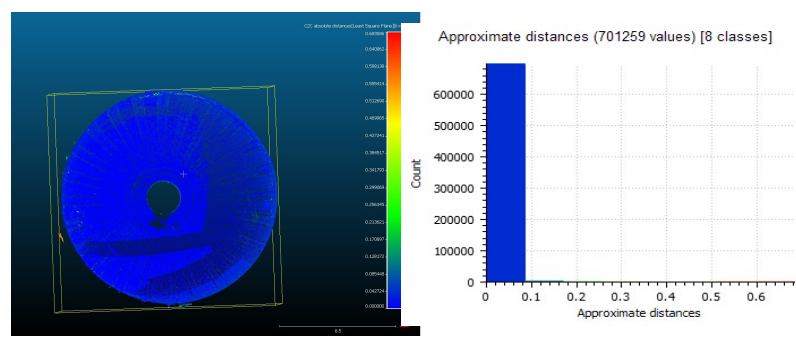

Figure 13: Discrepancy (m) map and histogram between the TLS point cloud and Regard 3D processing.

\section{DISCUSSION AND CONCLUSIONS}

The present study has shown as the interoperability of the three disciplines involved can allow not only an in-depth knowledge of constructive elements such as this dome of the Beata Vergine Assunta, but also to highlighting the potentialities of a multidisciplinary historic, material and geometric point of view, similarly in the study of other analogous case studies.

First of all, the documentary and archival research has been an essential starting point for understanding the stratigraphies and the possible ongoing causes of decay of the building materials, both original and from the later integrations. As found from the material analysis, it is clear that detachments of plasters and cracks can be originated not only from the infiltration of rainy waters but more especially from the scarce compatibility between old and new materials. But all these analyses and further geometric considerations cannot be carried out without an accurate survey of the dome, in this case compared between different geometric approaches.

In fact, more in detail, in the survey we tested a CRP system composed of two digital camera and two OS software and one commercial based with the SfM approach with the aim to assess the accuracy and functionality of an open source software and compare it to those already extensively tested by Photoscan, as well as to the 3D model coming from a TLS survey.

From table 3, 4 e 5 all the point clouds show a good accuracy with a standard deviation between $3.5 \mathrm{~cm}$ a $6.5 \mathrm{~cm}$.

Nevertheless, it can be considered that with VisualSfM the dome is not completely reconstructed (figure 7) whereas with Regard 3D even if it is completed, the cloud has a lower number of point than with Photoscan. Thus, even if both the use of VisualSfM and Regard 3D software were easy and immediate, with faster processing times especially compared to those of Photoscan, their use should be avoided for complex structures such as this dome and considered as an alternative in all the other cases where it is required a $3 \mathrm{D}$ reconstruction of buildings or structure quickly and not very accurately.

The research work also allowed to study two types of low cost digital camera and two methods of elaboration with Photoscan. The results obtained have made it possible to verify that for all calculation modalities and for both digital camera the geometric reconstruction is fairly faithful to the actual geometry obtained with the TLS. What changes in a decisive way is the number of points that compose the point cloud and the processing times of the dense clouds.

Overall, only with an accurate geometrical survey and its integration with different disciplines it is possible to have a complete knowledge of the fabric arriving at the understanding and the assessment of its current structural and materials issues for the definition of an intervention of conservation. 


\section{ACKNOWLEDGEMENTS}

This study was also supported by the project "Healthy Cities and Smart Territories", founded by the Foundation of Sardinia and Autonomous Region of Sardinia (Fondazione di Sardegna Convenzione triennale tra la Fondazione di Sardegna e gli Atenei Sardi Regione Sardegna 2016).

\section{REFERENCES}

Battini, C.; Vecchiattini, R.; 2017. Survey and restoration: New ways of interaction. Int. Arch. Photogramm. Remote Sens. Spat. Inf. Sci. 2017, 42-5/W1, 655-662.

Deidda, M.; Musa, C.; Vacca, G.; 2015. A GIS of Sardinia's Coastal defense system (XVI-XVIII century). Int. Arch. Photogramm. Remote Sens. Spat. Inf. Sci. 2015, 40-4/W7, 1722.

Fiorino, D. R., Grillo, S. M., Pilia, E. 2015. "Interdisciplinary Knowledge for Conservation of Ruins: Stratigraphic Investigations of San Giovanni Battista Church (Sardinia, Italy)". Athens: ATINER'S Conference Paper Series, No: ARC2015-2123.

Giannattasio, C.; Grillo, S.M.; Vacca, G.; 2013. Interdisciplinary study for knowledge and dating of the San Francesco Convent in Stampace, Cagliari - Italy (XIII-XXI Century), ISPRS Ann. Photogramm. Remote Sens. Spatial Inf. Sci., II-5/W1, 139-144, doi:10.5194/isprsannals-II-5-W1-1392013, eISSN 2194-9050

Szeliski, R., 2010. Computer vision: algorithms and applications. Springer.

Vacca, G.; Dessì, A.; Sacco, A., 2017. The Use of Nadir and Oblique UAV Images for Building Knowledge. ISPRS Int. J. Geo-Inf., 6, 393.

Vacca, G.; Mistretta, F.; Stochino, F.; Dessi, A., 2016. Terrestrial laser scanner for monitoring the deformations and the damages of buildings. In Proceedings of the International Archives of Photogrammetry, Remote Sensing and Spatial Information Sciences, pp. 453-460.

Virdis, F., Puddu, T. 2003. Gaetano Cima. Il tempio della villa di Guasila, documenti di archivio.

Westoby, M.J.; Brasington, J.; Glasser N.F.; Hambrey, M.J.; Reynolds, J.M., $2012 . \quad$ 'Structure-from-Motion' photogrammetry: a low-cost, effective tool for geoscience applications. Geomorphology, 179, pp. 300-314. 